\title{
PEMASARAN BERBASIS HUBUNGAN PADA KERJASAMA PERGURUAN TINGGI NEGERI: KASUS INSTITUT PERTANIAN BOGOR
}

\section{RELATIONSHIP MARKETING ON PUBLIC HIGHER EDUCATION: CASE IPB UNIVERSITY}

\author{
Sonya Dwi Rachmawati ${ }^{1 a}$, Heti Mulyati ${ }^{2}$, Megawati Simanjuntak ${ }^{3}$ \\ IProgram Manajemen dan Bisnis, Sekolah Bisnis, \\ Institut Pertanian Bogor, Kampus IPB Dramaga 16680 \\ ${ }^{2}$ Departemen Manajemen, Fakultas Ekonomi dan Manajemen, \\ Institut Pertanian Bogor, Kampus IPB Dramaga 16680 \\ ${ }^{3}$ Departemen Ilmu Keluarga dan Konsumen, Fakultas Ekologi Manusia \\ Institut Pertanian Bogor, Kampus IPB Dramaga 16680
}

${ }^{a}$ Korespondensi: Sonya Dwi Rachmawati, Telp/Hp: 08179143556, E-mail: sonya @apps.ipb.ac.id

\begin{abstract}
IPB University should implement its function: teaching, research and community services through collaboration with external partners, especially in national scope. However, the Memorandum of Understanding sometimes did not follow by concrete programs. In addition, the university should maintain string relationship to improve it partner's commitment. Therefore, it is necessary to analyze the factors of relationship marketing to IPB's partners. This study used survey methods to 100 respondents with questionnaire as the tool. The study used descriptive analysis to describe partner profiles and answers with top three boxes method. The results identified that based on location, partners were concentrated in Java with the most types of institutions are district and city governments. Cooperation initiators generally come from partners. The maximum duration of cooperation is 1-5 years. Number of collaboration 1-5 activities dominate partners. In general, partners are still actively collaborating with IPB, with more active MoU compared to those that are non-active. Trust has the highest perception value of respondents and followed by communication and shared values. Partner's perception of commitment to cooperation and satisfaction is good, while the benefits of cooperation are categorized sufficient. The variable relationship benefits need to be of concern to IPB and be improved by increasing competencies, human resources and appropriate technology that are applicable to the industrial world and local governments.
\end{abstract}

Key words: key mediating variable, relationship commitment, relationship marketing, satisfaction, trust.

\begin{abstract}
ABSTRAK
Institut Pertanian Bogor (IPB) harus mengimplementasikan fungsi tridharma yaitu pendidikan, penelitian dan pengabdian kepada masyarakat melalui kolaborasi dengan mitra eksternal, terutama dalam lingkup nasional. Namun, Nota Kesepahaman (MoU) terkadang tidak diikuti oleh program konkret. Selain itu, universitas harus menjaga hubungan baik untuk meningkatkan komitmen mitra. Oleh karena itu, perlu dilakukan analisis terhadap faktor-faktor pemasaran berbasis hubungan dengan mitra IPB. Penelitian ini menggunakan metode survei kepada 100 responden dengan alat bantu kuesioner.
\end{abstract}


Penelitian menggunakan analisis deskriptif untuk menjabarkan profil mitra dan pemilihan jawaban dengan metode top three boxes. Hasil mengidentifikasi bahwa berdasarkan lokasi, mitra terkonsentrasi di Pulau Jawa dengan jenis instansi terbanyak adalah pemerintah kabupaten dan kota. Inisiator kerjasama umumnya berasal dari mitra. Lama kerjasama paling banyak selama 1-5 tahun. Jumlah kerjasama 1-5 kegiatan mendominasi mitra. Umumnya mitra masih aktif bekerjasama dengan IPB, dengan MoU yang aktif lebih banyak dibandingkan dengan yang nonaktif. Kepercayaan memiliki nilai persepsi responden tertinggi dan sangat baik diikuti oleh komunikasi dan shared value. Persepsi mitra terhadap komitmen kerjasama dan kepuasan baik, sedangkan manfaat kerjasama dikategorikan cukup. Variabel manfaat kerjasama perlu menjadi perhatian IPB dan ditingkatkan dengan peningkatan kompetensi, sumber daya manusia serta teknologi tepat guna yang aplikatif bagi dunia industri dan pemerintah daerah.

Kata kunci: kepercayaan, komitmen hubungan, pemasaran berbasis hubungan, variabel mediasi kunci.

Sonya, S.D., Mulyati, H., \& Simanjuntak, M. (2019). Pemasaran Berbasis Hubungan Pada Kerjasama Perguruan Tinggi Negeri: Kasus Institut Pertanian Bogor, Tadbir Muwahhid, 3(2), 133-147

\section{PENDAHULUAN}

Pendidikan tinggi berada dalam lingkungan perubahan yang penuh dengan ketidakpastian sehingga harus terus berkembang mengikuti tuntutan masyarakat dan pemerintahan yang sangat dinamis (Bell et al. 2012). Perguruan tinggi dituntut selalu meningkatkan layanan dalam melaksanakan mandat tridharma yaitu pendidikan, penelitian dan pengabdian kepada masyarakat. Salah satu cara untuk meningkatkan daya saing adalah dengan meningkatkan kualitas pelayanan sehingga mampu memuaskan pelanggannya (Kotler dan Fox 1995). Untuk mengetahui kepuasan pelanggan khususnya mitra kerjasama dalam negeri, IPB telah melakukan survei kepuasan mitra kerjasama pada tahun 2018. Dhiranty et al. (2017) telah membuktikan bahwa terdapat hubungan antara kepuasan dan kepercayaan.
Peningkatan kualitas layanan dengan mitra dilakukan untuk meningkatkan dan mempertahankan hubungan kerjasama yang berkelanjutan. Morgan dan Hunt (1994) berpendapat bahwa hubungan tersebut berfungsi membangun, mengembangkan dan mempertahankan hubungan yang sukses dengan mitra dengan variabel positif dan negatif. Ahmady et al. (2012) mengonfirmasi bahwa komitmen lebih didorong oleh faktor yang positif dalam model yang ditemukan oleh Morgan dan Hunt (1994), faktor negatif seperti biaya pemutusan kerjasama tidak memberikan pengaruh yang signifikan terhadap komitmen. Selama ini penelitian hanya berfokus pada kepuasan mitra dalam bekerjasama, sehingga perlu dilakukan penelitian mengetahui komitmen berbasis hubungan dengan mitra. 
Nota kesepahaman bersama atau Memorandum of Understanding (MoU) merupakan salah satu dokumen kerjasama antara Institut Pertanian Bogor (IPB) dengan mitra. Dokumen tersebut bersifat umum yang memayungi kegiatan kerjasama selanjutnya. Program kerjasama yang konkret antara IPB dengan mitra dituangkan dalam Perjanjian Kerjasama (PKS). Semakin banyak kegiatan kerjasama yang dilakukan menunjukkan bahwa MoU dinilai telah dimanfaatkan secara optimal. Jumlah MoU aktif di IPB per Desember 2018 adalah 328 mitra. Namun demikian, ada beberapa MoU yang tidak diikuti oleh program konkret.

Hal penting lainnya adalah hubungan dengan mitra perlu dijaga untuk menciptakan keberlanjutan kerjasama yang sinergis. Selama ini, evaluasi kerjasama dengan mitra dilakukan melalui survei kepuasan. Umumnya para mitra tersebut merasa puas bekerjasama dengan IPB, terutama karena kualitas dan keahlian yang dimiliki IPB (Laporan Direktorat Kerjasama dan Hubungan Alumni IPB 2018). Akan tetapi, hal tersebut belum menunjukkan bahwa mitra akan bekerjasama secara kontinu dengan komitmen yang kuat. Komitmen tersebut dibangun melalui kepuasan dan kepercayaan. Oleh karena itu, kajian mengenai komitmen mitra berbasis hubungan dalam bekerjasama dengan IPB perlu dilakukan. Berdasarkan masalah tersebut, penelitian bertujuan untuk menganalisis profil mitra kerjasama IPB serta menganalisis tingkat kepuasan, komunikasi, shared value, kepercayaan, manfaat kerjasama dan komitmen kerjasama mitra IPB.

\section{METODE}

Penelitian merupakan penelitian kuantitatif dengan metode deskriptif. Sesuai dengan tujuan penelitian yaitu menganalisis profil mitra dan menganalisis variabel yang digunakan dalam penelitian dalam menilai kepercayaan dan komitmen mitra kerjasama IPB. Penelitian dilaksanakan di Institut Pertanian Bogor pada tanggal 6 Maret hingga 18 Mei 2019.

Subjek dalam penelitian adalah mitra kerjasama IPB yang mencakup mitra di dalam negeri dengan basis MoU yang bekerjasama dengan IPB selama 5 (lima) tahun terakhir. Berdasarkan data Direktorat Kerjasama dan Hubungan Alumni IPB Jumlah MoU aktif di IPB per Desember 2018 adalah 328 mitra. Teknik pengambilan sampel menggunakan metode purposive sampling. Pengambilan sampel dilakukan secara sengaja sesuai dengan ciri-ciri khusus seperti persyaratan sifat-sifat, karakteristik, ciri dan kriteria yang diperlukan sesuai dengan tujuan penelitian, ukuran sampel lebih dari 30 dan kurang dari 500 adalah tepat untuk kebanyakan penelitian (Sekaran dan Bougie, 2013). Dalam penelitian ini sampel yang digunakan 
sebanyak 100 mitra nasional. Jenis data terdiri dari data primer dan sekunder. Data primer diperoleh dengan menghubungi mitra melalui nomor telepon seluler dan aplikasi perpesanan WhatsApp untuk mengisi kuesioner. Kuesioner dikumpulkan melalui Google Docs dan e-mail, atau secara langsung. Data sekunder diperoleh dari berbagai penelitian, buku, jurnal dan laporan.

Variabel yang digunakan dalam penelitian adalah kepuasan, kepercayaan, komunikasi, shared value, manfaat kerjasama dan komitmen. Kepuasan menggunakan 5 indikator dan kepercayaan, komunikasi, shared value, manfaat kerjasama dan komitmen masing-masing dengan 3 indikator. Jumlah skala yang optimal berkisar antara empat hingga tujuh point dan skala yang lebih reliabel berkisar antara tujuh hingga sembilan jika dibandingkan dengan skala yang lebih pendek (Krosnik dan Fabrigar, 1997). Skala yang digunakan dalam penelitian ini adalah skala Likert dengan tujuh tingkat performance yaitu (1) sampai (7) untuk menyatakan respon "sangat tidak setuju" hingga "sangat setuju".

Analisis deskriptif berguna dalam menggambarkan profil mitra yang menjadi fokus penelitian. Deskripsi indikator dipaparkan dengan teknik top three boxes. Analisis top three boxes dalam mengukur kepuasan pelanggan memiliki keunggulan dalam menyediakan lebih banyak variasi dalam data sehingga lebih mudah untuk mengidentifikasi atribut di mana perusahaan berkinerja buruk (Sambandam dan Hausser, 1998). Jawaban responden dalam skala Likert 1-7 dipaparkan dengan teknik pengelolaan data secara top three boxes dan bottom three boxes menggunakan Microsoft Excel. Jawaban responden dikelompokkan menjadi tiga dengan pembagian skor 1-3 menyatakan respons tidak setuju, skor 4 menyatakan respons netral dan skor 5-7 menunjukkan respons setuju atas pernyataan dalam kuesioner.

\section{HASIL PENELITIAN DAN PEMBAHASAN}

\section{Profil Mitra}

Penelitian ini melibatkan responden yang berasal dari 100 mitra kerjasama yang dikategorikan berdasarkan beberapa kelompok mitra yang dihimpun sejak bulan Maret sampai dengan bulan Mei 2019. Setiap satu kontak mitra mewakili satu mitra kerjasama IPB atau Memorandum of Understanding (MoU). Karakteristik mitra dikelompokkan berdasarkan lokasi, jenis instansi, ruang lingkup kerjasama, unit kerjasama di IPB, inisiator kerjasama, lama kerjasama, jumlah kerjasama, tingkat keaktifan kerjasama dan keaktifan MoU. Profil mitra dalam penelitian ini disajikan pada Tabel 1.

\section{Tabel 1 Profil Mitra}




\begin{tabular}{|c|c|c|}
\hline Profil Mitra & Kategori & $\%$ \\
\hline \multicolumn{3}{|l|}{ Lokasi } \\
\hline & Sumatera & 1 \\
\hline & Jawa & 6 \\
\hline & Bali Nusa Tenggara & 3 \\
\hline & Kalimantan & 6 \\
\hline & Sulawesi & 1 \\
\hline & Papua & 2 \\
\hline \multicolumn{3}{|l|}{ Jenis } \\
\hline \multirow[t]{6}{*}{$\cdot \quad \cdots$} & BUMN & 1 \\
\hline & Pemerintah & 3 \\
\hline & Pemerintah Provinsi & 8 \\
\hline & Pemerintah Pusat & 1 \\
\hline & Perusahaan Swasta & 2 \\
\hline & Yayasan dan lain-lain & 6 \\
\hline \multicolumn{3}{|c|}{ Ruang lingkup kerjasama } \\
\hline & Pendidikan & 5 \\
\hline & Penelitian & 5 \\
\hline & PPM & 4 \\
\hline & Lain-lain* & 1 \\
\hline \multicolumn{3}{|c|}{ Unit kerjasama di IPB } \\
\hline & Fakultas & 5 \\
\hline & LPPM & 1 \\
\hline & Rektorat & 5 \\
\hline \multicolumn{3}{|c|}{ Inisiator kerjasama } \\
\hline & IPB & 3 \\
\hline & Mitra & 6 \\
\hline \multicolumn{3}{|c|}{ Lama bekerjasama dengan } \\
\hline & Kurang dari 1 tahun & 2 \\
\hline & $1-5$ tahun & 4 \\
\hline & lebih dari 5 tahun & 3 \\
\hline \multicolumn{3}{|c|}{ Jumlah kerjasama (bentuk } \\
\hline & 1 naskah & 3 \\
\hline & 1-5 naskah & 4 \\
\hline & Lebih dari 5 naskah & 1 \\
\hline \multicolumn{3}{|c|}{ Tingkat keaktifan kerjasama } \\
\hline & Sangat aktif & 2 \\
\hline & Aktif & 7 \\
\hline & Tidak aktif & 5 \\
\hline \multicolumn{3}{|c|}{ Keaktifan MoU } \\
\hline & Aktif & 6 \\
\hline & Nonaktif & 3 \\
\hline
\end{tabular}

\section{Lokasi}

Berdasarkan letak geografis, mitra nasional diklasifikasikan berdasarkan lokasi di pulau-pulau Indonesia. Bagi perusahaan swasta lokasi diidentifikasi berdasarkan kedudukan kantor, walaupun terdapat perusahaan multinasional yang memiliki area operasi di berbagai lokasi di Indonesia. Lokasi masih didominasi di pulau jawa khususnya propinsi DKI Jakarta sebanyak 64 persen diikuti di Sumatera dan Sulawesi masingmasing 15 persen dan sepuluh persen. Selanjutnya di pulau Kalimantan, Bali Nusa Tenggara dan Papua berturut-turut enam persen, tiga persen dan dua persen.

Hal ini juga menunjukkan komunikasi tim kerjasama IPB dan mitra dengan tingkat respon tertinggi berada pada mitra yang berada di pulau Jawa. Persebaran lokasi ini pun dapat menjadi pertimbangan bagi IPB untuk memperhatikan luas jangkauan mitra nasional agar dapat tersebar dan membuka peluang inisiasi kerjasama baru. Dengan demikian jangkauan mitra kerjasama tidak hanya berpusat di pulau jawa. Hal ini sesuai dengan saran yang diberikan mitra multinasional bahwa IPB diharapkan dapat meningkatkan kerjasama di luar Jawa.

\section{Jenis Instansi}

Sesuai dengan klasifikasi di IPB, jenis instansi mitra dikategorikan menjadi Badan Usaha Milik Negara (BUMN), pemerintah kabupaten/kota, pemerintah propinsi, pemerintah pusat, perusahaan swasta serta yayasan dan lain-lain. Jenis instansi terbanyak dalam penelitian ini adalah pemerintah kabupaten/kota sebanyak 30 persen dan perusahaan swasta sebanyak 27 
persen. Hal ini dapat disebabkan karena program pemerintah dipusatkan pada tingkat kabupaten/kota (desentralisasi), dimana kabupaten/kota memiliki kebutuhan yang spesifik sesuai dengan potensi dan kebutuhan daerah. Otonomi Daerah memberikan peluang berkembangnya nilai-nilai lokal sesuai ciri khas masing-masing Daerah (Nadir, 2013). Perusahaan swasta dengan jumlah mitra terbesar kedua, dapat menunjukkan hubungan IPB dengan Dunia Usaha dan Dunia Industri (DUDI) telah terjalin dengan cukup baik. Selanjutnya diikuti oleh pemerintah pusat dan BUMN masing-masing 16 persen dan 13 persen. Jumlah paling sedikit berasal dari instansi pada kelompok pemerintah provinsi serta yayasan dan lain-lain berturut-turut delapan persen dan enam persen.

\section{Ruang Lingkup Kerjasama}

Ruang lingkup diklasifikasikan sesuai dengan tridharma perguruan tinggi yaitu pendidikan, penelitian dan pengabdian kepada masyarakat serta lain-lain. Mitra IPB dalam penelitian didominasi dengan lingkup kerjasama bidang pendidikan dan penelitian dengan jumlah masing-masing 44 persen dan 40 persen. Pada lingkup lain-lain terdapat 13 persen mitra diantaranya merupakan kerjasama layanan perbankan, teknologi dan informasi, survei, konsultasi ahli/nara sumber, magang dan rekrutmen. Jumlah mitra terkecil berada pada lingkup pengabdian kepada masyarakat sebanyak 3 persen, hal ini dapat menjadi pertimbangan untuk perluasan mitra pada lingkup kerjasama tersebut.

\section{Unit Kerjasama di IPB}

Kategori unit kerjasama dibagi ke dalam 3 kelompok yaitu fakultas/departemen, LPPM dan Rektorat. Dalam penelitian ini mitra paling banyak bekerjasama dengan fakultas/departemen dengan proporsi 46 persen. Mitra juga banyak bekerjasama melalui rektorat sejumlah 39 persen dan paling sedikit bekerjasama dengan Lembaga Penelitian dan Pengabdian kepada Masyarakat (LPPM) sebanyak 15 persen. Kondisi ini lebih dikarenakan sumber responden yang bersumber dari LPPM belum banyak didapatkan oleh peneliti, karena secara data populasi kerjasama yang dilakukan di LPPM cukup banyak dan proporsional dibandingkan dengan fakultas serta lebih banyak dari rektorat. Seringkali mitra juga tidak dapat membedakan unit di IPB secara spesifik, mitra hanya mengetahui bekerjasama dengan IPB, tanpa mengetahui pasti unit di IPB khususnya dalam membedakan pusat penelitian dan departemen atau fakultas.

\section{Inisiator Kerjasama}

Inisiator kerjasama dikategorikan menjadi dua kelompok. Inisiasi lebih banyak dilakukan 
oleh mitra sebanyak 64 persen. Sedangkan inisiasi kerjasama yang dilakukan oleh IPB sebanyak 36 persen. Hal ini dapat menjadi peluang peningkatan inisiasi kerjasama dengan IPB. Sejalan dengan harapan mitra agar IPB proaktif dalam menawarkan program kerjasama kepada mitra, serta mengharapkan cakupan kerjasama yang lebih luas dari yang sudah dilaksanakan.

\section{Lama Kerjasama}

Mitra IPB dalam penelitian ini telah bekerjasama selama 1-5 tahun sebanyak 46 persen, lebih dari 5 tahun sebanyak 34 persen dan selebihnya sebanyak 20 persen telah bekerjasama kurang dari satu tahun. Hal ini dapat menunjukkan mitra cukup loyal terhadap IPB, di sisi lain terdapat indikasi kurangnya inisiasi terhadap mitra yang belum bekerjasama. Hal ini dapat menjadi alternatif peningkatan jumlah mitra kerjasama IPB.

\section{Jumlah Kerjasama}

Dalam penelitian ini, kerjasama yang dituangkan melalui perjanjian kerjasama sebanyak 1-5 kegiatan mendominasi mitra yaitu 49 persen. Mitra yang hanya bekerjasama pada satu kegiatan kerjasama sebanyak 35 persen dan hanya 16 persen mitra yang melaksanakan lebih dari lima kegiatan kerjasama dengan IPB. Hal ini dapat menjadi peluang perluasan cakupan dan bidang kerjasama khususnya bagi mitra yang hanya melakukan satu kegiatan saja. Hal ini sesuai dengan harapan mitra agar kerjasama dapat dikembangkan kepada bidang-bidang lain yang relevan dan bermanfaat bagi kedua belah pihak. Mitra juga memandang IPB harus lebih proaktif dalam menawarkan program kerjasama kepada mitra, agar kerjasamakerjasama di bidang lain lebih terbuka.

\section{Tingkat Keaktifan Kerjasama}

Dari 100 mitra yang menjadi responden dalam penelitian ini, hampir semua kerjasama sebanyak 95 persen masih aktif, yang terdiri dari 72 persen kerjasama yang aktif dan 23 persen kerjasama masih sangat aktif. Selisihnya sebanyak 5 persen menjadi peluang bagi IPB untuk dapat diaktifkan kembali karena berstatus tidak aktif sehingga kerjasama dapat dijalin kembali pada berbagai bidang.

\section{Keaktifan MoU}

Walaupun tingkat keaktifan kerjasama sangat tinggi yaitu 95 persen, namun berbeda halnya dengan Memorandum of Understanding (MoU). Terdapat 61 persen mitra yang memiliki MoU yang masih aktif dengan IPB, sedangkan sebanyak 39 persen MoU telah non aktif. Hal ini menjadi tantangan bagi IPB untuk memperbaiki hal terkait tertib administrasi kerjasama. Mitra berpendapat bahwa birokrasi dan rantai administrasi melalui rektorat perlu disederhanakan. Hal ini 
disebabkan karena kegiatan lapangan khususnya, membutuhkan dukungan cepat melalui keputusan para pejabat pemegang otoritas administrasi, sehingga jika ada kendala di lapangan dapat cepat diatasi. Mitra berpendapat bahwa keputusan administrasi terlalu kaku dan berhubungan dengan banyak pemangku namun seringkali para pemangku jabatan tidak berada di tempat, sehingga seringkali proses administrasi terhambat. Mitra juga menyarankan agar implementasi MoU dapat lebih dioptimalkan, bentuk kerjasama lain dapat dibuka dan kerjasama yang lebih operasional dapat dilaksanakan.

\section{Analisis Kepuasan, Kepercayaan,}

Komunikasi, Shared Value, Manfaat dan

Komitmen Kerjasama

\section{Kepuasan Layanan Kerjasama IPB}

Kepuasan merupakan perasaan seseorang yang muncul apakah senang atau kecewa, setelah melakukan perbandingan antara kinerja atau hasil produk yang diterima dengan kinerja atau hasil yang ingin diperoleh, jika performance yang diterima dari suatu barang atau jasa melebihi apa yang diharapkan maka konsumen akan merasakan puas (Supranto 2001). Kepuasan menggunakan lima indikator dan masingmasing indikator dibagi ke dalam dua pernyataan. Kepuasan mitra didefinisikan sebagai sikap, penilaian dan respons emosional yang dirasakan dan ditunjukkan oleh mitra IPB setelah mendapatkan layanan kerjasama dari IPB.

Dari hasil perhitungan top three boxes dapat diketahui bahwa tingkat kepuasan mitra terhadap layanan kerjasama IPB baik, 87 dari 100 responden menyatakan kepuasan terhadap layanan IPB. Tim IPB memberikan layanan sepenuh hati (SF42), proses naskah kerjasama cepat dan tepat (SF51) serta prosedur mudah dan tidak berbelit-belit (SF52) dikonfirmasi oleh mitra sebanyak 92 persen.

Mitra menilai layanan sepenuh hati (SF42) merupakan hal yang paling dirasakan dengan nilai rata-rata tertinggi sebesar 6.24. Tidak ada mitra yang merasakan bahwa IPB tidak memberikan layanan sepenuh hati. Tangible, merupakan indikator yang paling rendah dibandingkan indikator lain. Mitra umumnya menilai lokasi IPB yang tidak mudah dijangkau (SF31). Kemudahan lokasi dikonfirmasi oleh 70 persen mitra dan 10 persen mitra menilai lokasi IPB tidak mudah dijangkau dengan rata-rata nilai terendah yaitu 5.20. Hal ini karena lokasi IPB berada di luar kota dan seringkali terjadi kemacetan dalam perjalanan menuju kampus IPB karena banyaknya kendaraan bermotor dan jalan yang sempit serta minimnya akses jalan alternatif. Hasil pengukuran kepuasan mitra IPB ditunjukkan Tabel 2. 
Tabel 2 Sebaran responden berdasarkan kepuasan layanan kerjasama IPB

\begin{tabular}{|c|c|c|c|c|c|}
\hline \multirow[t]{3}{*}{$\begin{array}{l}\text { Kod } \\
\text { e }\end{array}$} & \multirow[t]{3}{*}{ Indikator } & \multirow[t]{3}{*}{ Setuju } & \multirow[t]{3}{*}{$\begin{array}{l}\text { Net } \\
\text { ral }\end{array}$} & \multirow{3}{*}{$\begin{array}{l}\text { Tidak } \\
\text { Setuju }\end{array}$} & $\begin{array}{l}\text { Rat } \\
\text { a- } \\
\text { rata } \\
\text { (ska }\end{array}$ \\
\hline & & & & & la \\
\hline & & & & & 1-7) \\
\hline $\begin{array}{l}\mathrm{SF} \\
11\end{array}$ & $\begin{array}{l}\text { Proaktif dalam implementasi tindak lanjut } \\
\text { MoU }\end{array}$ & $\begin{array}{l}81 . \\
0\end{array}$ & $\begin{array}{l}1 \\
4 . \\
0\end{array}$ & 5.0 & $\begin{array}{l}5.5 \\
5\end{array}$ \\
\hline SF & & & 1 & & \\
\hline 12 & $\begin{array}{l}\text { Tanggap terhadap rencana dan pelaksanaan } \\
\text { kerjasama }\end{array}$ & $\begin{array}{l}86 . \\
0\end{array}$ & $\begin{array}{l}0 . \\
0\end{array}$ & 4.0 & $\begin{array}{l}5.7 \\
7\end{array}$ \\
\hline SF & & 89. & 8. & & 5.8 \\
\hline 21 & Implementasi kerjasama sesuai $\mathrm{MoU}$ & 0 & $\begin{array}{l}0 \\
1\end{array}$ & 3.0 & 2 \\
\hline $\begin{array}{l}\text { SF } \\
22\end{array}$ & $\begin{array}{l}\text { Dukungan institusi untuk melaksanakan } \\
\text { kerjasama yang baik }\end{array}$ & $\begin{array}{l}89 . \\
0\end{array}$ & $\begin{array}{l}0 . \\
0 \\
2\end{array}$ & 1.0 & $\begin{array}{l}6.0 \\
0\end{array}$ \\
\hline $\begin{array}{l}\text { SF } \\
31\end{array}$ & Lokasi mudah dijangkau & $\begin{array}{l}70 . \\
0\end{array}$ & $\begin{array}{l}0 . \\
0\end{array}$ & $\begin{array}{l}10 . \\
0\end{array}$ & $\begin{array}{l}5.2 \\
0\end{array}$ \\
\hline $\begin{array}{l}\mathrm{SF} \\
32\end{array}$ & Fasilitas kantor yang baik & $\begin{array}{l}91 . \\
0\end{array}$ & $\begin{array}{l}8 . \\
0\end{array}$ & 1.0 & $\begin{array}{l}5.9 \\
0\end{array}$ \\
\hline $\begin{array}{l}\text { SF } \\
41\end{array}$ & Tim ramah dan hangat & $\begin{array}{l}91 . \\
0\end{array}$ & $\begin{array}{l}8 . \\
0\end{array}$ & 1.0 & $\begin{array}{l}5.9 \\
0\end{array}$ \\
\hline $\begin{array}{l}\text { SF } \\
42\end{array}$ & Layanan sepenuh hati & $\begin{array}{l}92 . \\
0\end{array}$ & $\begin{array}{l}8 . \\
0\end{array}$ & 0.0 & $\begin{array}{l}6.2 \\
4\end{array}$ \\
\hline $\mathrm{SF}$ & & 92. & 7. & & 5.9 \\
\hline 51 & Proses naskah kerjasama cepat dan tepat & 0 & 0 & 1.0 & 2 \\
\hline $\mathrm{SF}$ & & 92. & 7. & & 6.0 \\
\hline 52 & Prosedur mudah dan tidak berbelit-belit & 0 & 0 & 1.0 & 2 \\
\hline & & 87. & 10. & & 5.8 \\
\hline & & 3 & 0 & 2.7 & 3 \\
\hline
\end{tabular}

Kepercayaan terhadap Tim Kerjasama IPB

Kepercayaan merupakan suatu penilaian oleh konsumen terhadap penyedia jasa yang mencakup rasa aman serta harapan konsumen yang terpenuhi (Zeithaml et al. 2006). Kepercayaan menggunakan tiga indikator dan setiap indikator dibagi ke dalam dua pernyataan. Kepercayaan mitra merupakan kemauan individu sebagai representasi mitra untuk mengandalkan IPB melakukan tindakan tertentu untuk kepentingan mitra terlepas dari kemampuan mitra untuk memantau dan mengendalikan IPB.

Berdasarkan hasil perhitungan top three boxes dapat diketahui bahwa tingkat kepercayaan mitra kepada IPB sangat baik dengan rata-rata persentase 93.5 dan rata-rata bernilai 6.17. Kompetensi tim IPB dinilai baik oleh hampir seluruh mitra (TR32) dengan 97 persen responden dan 3 persen memilih netral, tidak ada mitra yang tidak percaya terhadap kompetensi tim IPB. Mitra menilai terkait tepat janjinya tim IPB (TR21) sebanyak 91 persen, ini merupakan indikator yang paling rendah bagi mitra, terdapat 2 persen mitra yang menilai tim IPB tidak tepat janji. Tepat janji merupakan indikator paling rendah dengan nilai rata-rata 5.95. Selain itu juga terdapat 1 mitra yang mengalami kelalaian IPB dalam memenuhi kesepakatan. Hal ini dapat menjadi peluang perbaikan bagi IPB untuk meningkatkan kepercayaan mitra dan sangat penting dalam mempertahankan mitra. Diantaranya terdapat mitra yang menyarankan agar perkembangan kerjasama dapat cepat diinformasikan. Mitra juga kesulitan dalam mengatur waktu pertemuan karena kesibukan dan padatnya jadwal tim kerjasama IPB. Salah satu mitra menyarankan agar tim kerjasama IPB bekerja sesuai dengan tuntutan dan tidak melakukan subkontrak kepada pihak lain. Selengkapnya hasil pengukuran kepercayaan mitra terhadap IPB disajikan pada Tabel 3.

Tabel 3 Sebaran responden berdasarkan kepercayaan tim kerjasama IPB

\begin{tabular}{llcccc}
\hline $\begin{array}{l}\text { Kod } \\
\mathrm{e}\end{array}$ & Indikator & Setuju & Netral $\begin{array}{l}\text { Tidak } \\
\text { Setuj } \\
\mathrm{u}\end{array}$ & $\begin{array}{l}\text { Rata } \\
\text {-rata } \\
\text { (ska } \\
\text { la 1- } \\
7 \text { ) }\end{array}$ \\
\hline TR11 & Tim kerjasama jujur & 93.0 & 7.0 & 0.0 & 6.24 \\
TR12 & Tim kerjasama tulus & 93.0 & 7.0 & 0.0 & 6.19
\end{tabular}




\begin{tabular}{llcccc} 
TR21 & $\begin{array}{l}\text { Tepat janji } \\
\text { tidak pernah lalai memenuhi }\end{array}$ & 91.0 & 7.0 & 2.0 & 5.95 \\
TR22 & 92.0 & 7.0 & 1.0 & 6.02 \\
kR31 & Ahli di bidang kerjasamanya & 95.0 & 5.0 & 0.0 & 6.29 \\
& & 97.0 & 3.0 & 0.0 & 6.33 \\
\hline TR32 & Kompetensi yang baik & 93.5 & 6.0 & 0.5 & 6.17 \\
\hline & Rata-rata persentase & & & &
\end{tabular}

\section{Komunikasi IPB dengan Mitra}

Komunikasi merupakan proses yang dilakukan oleh individu dalam hubungan, kelompok, organisasi dan masyarakat dengan menggunakan informasi untuk berhubungan satu sama lain dengan lingkungannya (Ruben dan Stewart 2006). Komunikasi menggunakan tiga indikator dan masingmasing indikator dibagi ke dalam dua pernyataan.

Komunikasi IPB didefinisikan sebagai sarana atas proses yang dilakukan oleh individu-individu IPB dalam hubungan kerjasama dengan menggunakan informasi untuk berhubungan dengan individu-individu yang merupakan representasi mitra kerjasama yang mempertemukan kebutuhan dan tujuan kedua belah pihak. Berdasarkan hasil perhitungan top three boxes dapat diketahui bahwa komunikasi IPB terhadap mitra sangat baik, dengan rata-rata persentase 90.8 dan rata-rata indikator bernilai 5.92 .

Tim kerjasama IPB memberikan pemahaman yang baik dalam bekerjasama (CM32), hal ini disetujui oleh 94 persen mitra dan terdapat satu persen mitra menilai IPB tidak memberikan pemahaman yang baik. Kemampuan komunikasi Tim IPB yang baik dalam bekerjasama (CM31), memiliki rata- rata penilaian terbaik yaitu 6.12 dan tidak ada mitra yang tidak mengonfirmasi. Terdapat empat persen mitra yang kesulitan menghubungi tim IPB (CM22) dan 88 persen lainnya tidak mengalami hambatan dalam menghubungi tim IPB. Mitra sebanyak 87 persen menilai bahwa tim kerjasama IPB selalu menginformasikan perkembangan terbaru kerjasama (CM11). Komunikasi merupakan faktor kunci dalam bekerjasama. Komunikasi yang tepat waktu dapat mengembangkan kepercayaan dengan membantu menyelesaikan perselisihan dan menyelaraskan antara persepsi dengan harapan (Morgan dan Hunt 1994). Dengan komunikasi yang baik, masalah-masalah dapat segera diselesaikan sebelum menimbulkan masalah baru. Diantaranya terdapat mitra yang menyarankan agar perkembangan kerjasama dapat cepat diinformasikan dengan komunikasi yang baik dan efektif. IPB juga diharapkan lebih aktif mengekspos ke media tentang kerjasama yang bisa dilakukan dan mengekspos bidang apa saja yang dapat menjadi bidang kerjasama. Hasil pengukuran komunikasi IPB terhadap mitra ditunjukkan oleh Tabel 4.

Tabel 5 Sebaran responden berdasarkan komunikasi IPB

\begin{tabular}{|c|c|c|c|c|c|}
\hline $\begin{array}{l}\text { Ko } \\
\text { de }\end{array}$ & Indikator & $\begin{array}{l}\text { Set } \\
\text { uju }\end{array}$ & $\begin{array}{l}\text { Net } \\
\text { ral }\end{array}$ & $\begin{array}{l}\text { Tid } \\
\text { ak } \\
\text { Set } \\
\text { uju }\end{array}$ & $\begin{array}{l}\text { Rata- } \\
\text { rata } \\
\text { (skal } \\
\text { a 1- } \\
\text { 7) }\end{array}$ \\
\hline $\begin{array}{l}\mathrm{C} \\
\mathrm{M} 1 \\
1\end{array}$ & $\begin{array}{l}\text { Selalu menginformasikan } \\
\text { perkembangan baru kerjasama }\end{array}$ & $\begin{array}{l}87 . \\
0\end{array}$ & $\begin{array}{l}11 . \\
0\end{array}$ & 2.0 & $\begin{array}{l}5.6 \\
8\end{array}$ \\
\hline $\begin{array}{l}\text { C } \\
\text { M1 } \\
2\end{array}$ & $\begin{array}{l}\text { Mitra mudah mendapatkan } \\
\text { informasi terbaru kerjasama }\end{array}$ & $\begin{array}{l}91 . \\
0\end{array}$ & 7.0 & 2.0 & $\begin{array}{l}5.7 \\
4\end{array}$ \\
\hline
\end{tabular}




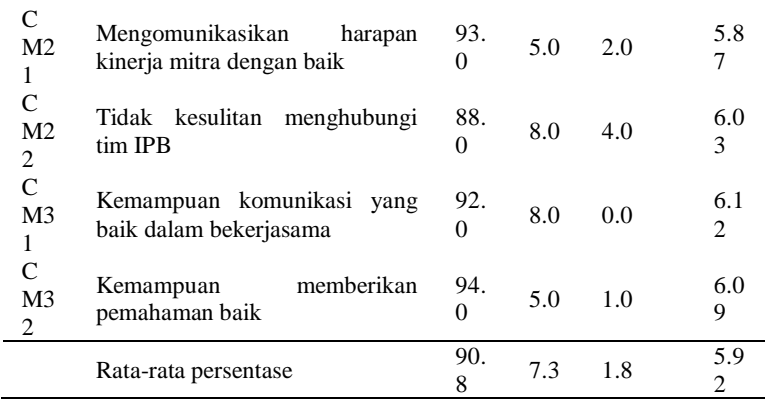

\section{Shared value IPB dan Mitra}

Shared value merupakan ukuran sejauh mana mitra memiliki kepercayaan yang sama tentang perilaku, tujuan dan kebijakan apa yang penting dan tidak penting, tepat atau tidak tepat dan benar atau salah (Morgan dan Hunt 1994). Shared value menggunakan tiga indikator dan masing-masing indikator dibagi ke dalam dua pernyataan. Shared value merupakan ukuran sejauh mana mitra memiliki nilai yang sama dengan IPB terkait dengan perilaku, tujuan dan kebijakan yang berhubungan dengan penting atau tidak penting, tepat atau tidak tepat serta benar atau salah. Berdasarkan hasil perhitungan top three boxes dapat diketahui bahwa shared value IPB dan mitra sangat baik, dengan ratarata persentase 90.2 dan rata-rata nilai 6.06.

Indikator pentingnya nilai bagi mitra IPB (SV3) dominan dan dikonfirmasi 95 persen mitra. Mitra menilai bahwa IPB memegang nilai-nilai etika dalam kerjasama yang terjalin (SV31) dan Mitra memegang teguh nilai dan norma dalam bekerjasama dengan IPB (SV32). Para pihak dalam kerjasama menjaga nilai dan norma yang dianut oleh masing-masing pihak. Mitra memandang perlunya kompromi etika untuk keberhasilan kerjasama dan dikonfirmasi 75 persen mitra sedangkan 6 persen tidak menyetujui pernyataan tersebut. Selengkapnya Shared Value IPB dan Mitra IPB disajikan pada Tabel 6.

Tabel 6 Sebaran responden berdasarkan shared value tim kerjasama IPB

\begin{tabular}{llllll}
\hline $\begin{array}{l}\text { Kod } \\
\mathrm{e}\end{array}$ & Indikator & $\begin{array}{l}\text { Setuj } \\
\mathrm{u}\end{array}$ & $\begin{array}{l}\text { Netr } \\
\mathrm{al}\end{array}$ & $\begin{array}{l}\text { Tida } \\
\mathrm{k} \\
\text { Setuj } \\
\mathrm{u}\end{array}$ & $\begin{array}{l}\text { Rata } \\
\text {-rata } \\
\text { (skal } \\
\text { a 1 }\end{array}$ \\
\hline SV11 \\
SV12 & $\begin{array}{l}\text { Diperlukan kompromi etika untuk keberhasilan } \\
\text { kerjasama }\end{array}$ & 75.0 & 19.0 & 6.0 & 5.37 \\
Tidak ada hambatan etika dalam komunikasi & 93.0 & 7.0 & 0.0 & 6.13 \\
SV21 & Tidak menunjukkan perilaku tidak etis & 91.0 & 7.0 & 2.0 & 6.13 \\
SV22 & $\begin{array}{l}\text { Tidak melanggar norma/berbuat } \\
\text { curang/menghasilkan keuntungan sendiri }\end{array}$ & 92.0 & 7.0 & 1.0 & 6.22 \\
SV31 & Memegang nilai etika & & & & \\
SV32 & Memegang teguh nilai dan norma & 95.0 & 5.0 & 0.0 & 6.29 \\
\hline & Rata-rata persentase & 95.0 & 5.0 & 0.0 & 6.24 \\
\hline & & 90.2 & 8.3 & 1.5 & 6.06 \\
\hline
\end{tabular}

\section{Manfaat Kerjasama dengan IPB}

Manfaat kerjasama menggunakan tiga indikator dan setiap indikator terdiri atas dua pernyataan. Manfaat kerjasama didefinisikan sebagai kualitas layanan kerjasama yang diberikan IPB dalam kerjasama yang dapat diperbandingkan dengan mitra lain yang memiliki kesamaan dengan IPB (Morgan dan Hunt 1994). Berdasarkan hasil perhitungan top three boxes dapat diketahui bahwa manfaat kerjasama IPB terhadap mitra cukup dengan rata-rata persentase 60.8 dan rata-rata indikator nilai 4.82. Hasil pengukuran manfaat kerjasama secara lengkap disajikan pada tabel 7. 
Tabel 7 Sebaran responden berdasarkan manfaat kerjasama dengan IPB

\begin{tabular}{|c|c|c|c|c|c|}
\hline $\begin{array}{l}\text { Ko } \\
\text { de }\end{array}$ & Indikator & $\begin{array}{l}\text { Setu } \\
\text { ju }\end{array}$ & $\begin{array}{l}\text { Netr } \\
\text { al }\end{array}$ & $\begin{array}{l}\text { Tid } \\
\text { ak } \\
\text { Setu } \\
\text { ju }\end{array}$ & $\begin{array}{l}\text { Rat } \\
\text { a- } \\
\text { rata } \\
\text { (ska } \\
\text { la } \\
1-7 \text { ) }\end{array}$ \\
\hline $\begin{array}{l}\mathrm{RB} \\
11\end{array}$ & $\begin{array}{l}\text { Mitra lain menghasilkan keluaran } \\
\text { lebih buruk di bidang yang sama }\end{array}$ & 43.0 & 30.0 & 27.0 & $\begin{array}{l}4.2 \\
7\end{array}$ \\
\hline $\begin{array}{l}\mathrm{RB} \\
12\end{array}$ & $\begin{array}{l}\text { Bekerjasama dengan IPB lebih } \\
\text { bermanfaat dibanding mitra lain }\end{array}$ & 56.0 & 29.0 & 15.0 & $\begin{array}{l}4.7 \\
7\end{array}$ \\
\hline $\begin{array}{l}\mathrm{RB} \\
21\end{array}$ & $\begin{array}{l}\text { Kinerja kerjasama mitra lain } \\
\text { lebih buruk }\end{array}$ & 32.0 & 30.0 & 38.0 & $\begin{array}{l}3.7 \\
7\end{array}$ \\
\hline $\begin{array}{l}\mathrm{RB} \\
22\end{array}$ & $\begin{array}{l}\text { Kinerja IPB lebih baik dibanding } \\
\text { mitra sejenis }\end{array}$ & 60.0 & 28.0 & 12.0 & $\begin{array}{l}4.8 \\
9\end{array}$ \\
\hline $\begin{array}{l}\mathrm{RB} \\
31\end{array}$ & Manfaat sesuai harapan & 91.0 & 8.0 & 1.0 & $\begin{array}{l}5.7 \\
9\end{array}$ \\
\hline $\begin{array}{l}\mathrm{RB} \\
32\end{array}$ & $\begin{array}{l}\text { Manfaat lebih dari yang } \\
\text { diharapkan }\end{array}$ & 83.0 & 15.0 & 2.0 & $\begin{array}{l}5.4 \\
0\end{array}$ \\
\hline & Rata-rata persentase & 60.8 & 23.3 & 15.8 & $\begin{array}{l}4.8 \\
2\end{array}$ \\
\hline
\end{tabular}

Manfaat kerjasama dengan IPB dinilai sesuai harapan (RB31) oleh 91 persen mitra, bahkan 83 persen mitra menilai bahwa manfaat kerjasama yang dilaksanakan lebih dari yang diharapkan (RB32). Mitra menilai kinerja kerjasama mitra lain selain IPB lebih buruk (RB21) sebanyak 32 persen, dan sebaliknya sebanyak 38 persen mitra menilai kerjasama mitra lain memiliki kinerja sama atau lebih baik dari IPB. Hal ini perlu menjadi perhatian khusus bagi IPB, dikuatirkan mitra dapat beralih kepada mitra selain IPB yang mampu memberikan keluaran yang lebih baik. Untuk mempertahankan mitra, manfaat kerjasama harus menjadi prioritas dalam peningkatan layanan kerjasama IPB.

\section{Komitmen Kerjasama dengan IPB}

Komitmen kerjasama menggunakan tiga indikator dan masing-masing indikator dibagi ke dalam dua pernyataan. Komitmen kerjasama didefinisikan sebagai pertukaran kepercayaan mitra dan IPB bahwa hubungan yang berkelanjutan kedua belah pihak sangat penting dalam menjamin upaya maksimal untuk mempertahankan kerjasama yang dilakukan dalam jangka panjang. Berdasarkan hasil perhitungan top three boxes dapat diketahui bahwa komitmen kerjasama yang baik dari mitra terhadap IPB dengan rata-rata persentase 88.0 dan rata-rata skor bernilai 5.90. Indikator yang paling dominan bagi mitra adalah kerjasama pantas dipertahankan (RC3), 93 persen mitra menilai kerjasama pantas dipertahankan secara maksimal (RC31) dan menjaga kerjasama dengan semaksimal mungkin (RC32). Namun hanya 65 persen mitra yang tidak berniat beralih ke mitra lain yang sejenis (RC12), terdapat 12 persen mitra berniat untuk beralih ke mitra lain. Hasil pengukuran komitmen kerjasama dapat dilihat pada tabel 7 .

Tabel 8 Sebaran responden berdasarkan komitmen kerjasama dengan IPB

\begin{tabular}{|c|c|c|c|c|c|}
\hline $\begin{array}{l}\text { Kod } \\
\text { e }\end{array}$ & Indikator & $\begin{array}{l}\text { Setuj } \\
\text { u }\end{array}$ & $\begin{array}{l}\text { Netra } \\
1\end{array}$ & $\begin{array}{l}\text { Tidak } \\
\text { Setuj } \\
\text { u }\end{array}$ & $\begin{array}{l}\text { Rata- } \\
\text { rata } \\
\text { (skal } \\
\text { a 1- } \\
\text { 7) }\end{array}$ \\
\hline $\begin{array}{l}\mathrm{RC} 1 \\
1\end{array}$ & Mitra sangat berkomitmen kuat & 93.0 & 6.0 & 1.0 & 5.93 \\
\hline $\begin{array}{l}\mathrm{RC} 1 \\
2\end{array}$ & $\begin{array}{l}\text { Mitra tidak berniat beralih ke mitra lain yang } \\
\text { sejenis }\end{array}$ & 65.0 & 23.0 & 12.0 & 5.01 \\
\hline $\begin{array}{l}\mathrm{RC} 2 \\
1\end{array}$ & Hubungan akan dipertahankan & 90.0 & 9.0 & 1.0 & 5.90 \\
\hline $\begin{array}{l}\mathrm{RC} 2 \\
2\end{array}$ & $\begin{array}{l}\text { Mitra menjaga kerjasama agar terlaksana dengan } \\
\text { baik }\end{array}$ & 93.0 & 7.0 & 0.0 & 6.15 \\
\hline $\begin{array}{l}\mathrm{RC} 3 \\
1\end{array}$ & $\begin{array}{l}\text { Kerjasama } \\
\text { maksimal }\end{array}$ pantas dipertahankan dengan & 93.0 & 7.0 & 0.0 & 6.18 \\
\hline \multirow[t]{2}{*}{$\begin{array}{l}\mathrm{RC} 3 \\
2\end{array}$} & Mitra menjaga kerjasama semaksimal mungkin & 94.0 & 6.0 & 0.0 & 6.23 \\
\hline & Rata-rata persentase & 88.0 & 9.7 & 2.3 & 5.90 \\
\hline
\end{tabular}

Berdasarkan hasil perhitungan top three boxes, tingkat kepercayaan mitra pada IPB sangat baik dengan rata-rata persentase 93.5 persen. Hanya enam persen mitra yang netral dan sangat sedikit mitra yang tidak 
memiliki kepercayaan terhadap IPB.

Kompetensi tim IPB dinilai baik oleh hampir seluruh mitra. Selanjutnya dari yang tertinggi berturut-turut komunikasi, shared value, kepuasan dan komitmen kerjasama masingmasing 90.8 persen, 90.2 persen, 87.3 persen dan 88 persen dengan mitra yang memilih netral berkisar enam hingga sepuluh persen, dan dibawah tiga persen yang berada pada bottom three boxes pada semua variabel kecuali manfaat kerjasama.

Sedangkan manfaat kerjasama IPB terhadap mitra cukup (60.8 persen). Bahkan 23.3 persen mitra netral dan sisanya 15.8 persen menilai manfaat kerjasama dengan IPB tidak lebih baik jika dibandingkan dengan mitra lain yang dapat melakukan kerjasama yang sejenis dengan apa yang sudah dilakukan dengan IPB. Manfaat kerjasama harus menjadi prioritas perbaikan, karena memiliki nilai yang jauh dibawah variabel lain. Dari hasil tersebut, manfaat kerjasama perlu menjadi perhatian khusus dalam peningkatan layanan kerjasama IPB. Selengkapnya deskripsi indikator disajikan pada Gambar 1.

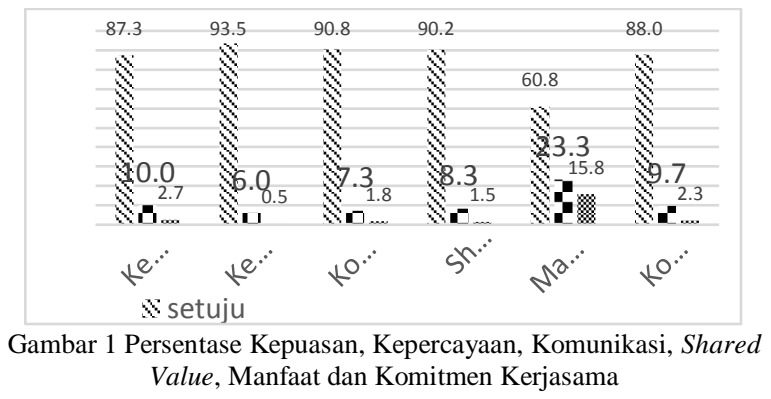

\section{KESIMPULAN DAN IMPLIKASI}

\section{Kesimpulan}

Berdasarkan lokasi, mitra terkonsentrasi di Pulau Jawa. Jenis instansi terbanyak adalah pemerintah kabupaten dan kota. Berdasarkan ruang lingkup kerjasama mitra didominasi pada bidang pendidikan. Unit kerjasama di IPB paling banyak pada fakultas/departemen. Inisiator kerjasama umumnya berasal dari mitra. Lama kerjasama yang paling banyak adalah selama 1-5 tahun. Jumlah kerjasama 1-5 kegiatan mendominasi mitra. Umumnya mitra masih aktif bekerjasama dengan IPB dengan MoU yang aktif lebih banyak dari yang nonaktif.

Dari enam variabel yang digunakan dalam penelitian yaitu kepuasan, kepercayaan, komunikasi, shared value, manfaat kerjasama dan komitmen terdapat lima variabel yang terkategori baik dan satu cukup. Berdasarkan hasil perhitungan top three boxes, tingkat kepercayaan mitra pada IPB sangat baik. Kompetensi tim IPB dinilai baik oleh hampir seluruh mitra. Selanjutnya dari yang tertinggi berturut-turut komunikasi, shared value, kepuasan dan komitmen kerjasama. Sedangkan manfaat kerjasama IPB terhadap mitra cukup. Dari hasil tersebut, manfaat kerjasama perlu menjadi perhatian khusus dalam peningkatan layanan kerjasama IPB.

\section{Implikasi}


Manfaat bersama merupakan hal yang perlu menjadi prioritas dalam meningkatkan komitmen dan kepercayaan mitra kerjasama IPB. Untuk meningkatkan manfaat bersama perlu dilakukan beberapa langkah yaitu: peningkatan kompetensi, sumber daya manusia serta teknologi tepat guna yang aplikatif bagi dunia industri dan pemerintah daerah.

Pertama, peningkatan kompetensi dapat dilakukan dengan peningkatan inovasi dan kualitas kompetensi serta pemerataan kompetensi sehingga suatu keahlian tidak hanya dimiliki oleh seseorang dan dilakukan kaderisasi dari tim ahli yang sudah senior. Hal ini juga bermanfaat menjaga kompetensi secara korporasi pada tingkat IPB. Kedua, peningkatan sumber daya manusia dilakukan melalui pendidikan formal dan informal serta pelatihan baik sesuai dengan kompetensi maupun dalam bidang manajerial dan soft skill. Ketiga, teknologi tepat guna yang aplikatif bagi dunia industri dan pemerintah dilakukan dengan memaksimalkan inovasi IPB yang selain dipublikasikan dalam tulisan ilmiah juga dilakukan suatu manajemen inovasi IPB. Inovasi juga dibuat berdasarkan kebutuhan industri and daerah untuk pengembangan daerah.

\section{DAFTAR PUSTAKA}

[IPB DKHA] Institut Pertanian Bogor, Direktorat Kerjasama dan Hubungan
Alumni. 2018. Laporan Tahunan Direktorat Kerjasama dan Hubungan Alumni. Bogor : Institut Pertanian Bogor.

Muchlis Ahmady. (2012). Model Pemasaran Berbasis Hubungan pada Agribisnis: Kasus pada Saluran Pemasaran di Jawa Barat. Disertasi, tidak dipublikasikan. Institut Pertanian Bogor.

Bell G, Warwick G, Galbraith P.(2012). Higher Education Management and Operational Research: Demonstrating New Practices and Metaphors. Sense Publishers [internet]. [diunduh 2018 Nov 18]; 3(28), yang tersedia di: https://www.sensepublishers.com/medi a/1426-higher-education-managementand-operational-research.pdf.

Dhiranty A, Suharjo, B, Suprayitno G. (2017). An Analysis on Customer Satisfaction, Trust and Loyalty Toward Online Shop (A Case Study of Tokopedia.Com). Indonesian Journal of Business and Entrepreneurship (IJBE), $\quad 3(2), \quad 102$. doi:https://doi.org/10.17358/ijbe.3.2.10 2

Kotler P, Fox KFA. (1995). Strategic Marketing for Educational Institutions. Englewood Cliffs, New York: PrenticeHall.

Krosnik JA, Fabrigar LR. (1997). Designing Rating Scales for Effective Measurement in Surveys. Survey Measurement and Process Quality. New York: John Wiley.

Morgan R, Hunt S. (1994). The CommitmentTrust Theory of relationship marketing. Journal of marketing. 58(3):20-38. doi $: 10.2307 / 1252308$

Nadir S. (2013). Otonomi daerah dan desentralisasi Desa: Menuju pemberdayaan masyarakat desa. Jurnal Politik Provetik. 1(1). Retrieved July 19, 2019 from http://journal.uinalauddin.ac.id/index.php/jpp/article/do wnload/1621/1573

Parasuraman A, Zeithaml V, Berry LL. (1990). Delivering Quality Service: Balancing Costumer Perception and 
Expectations. New York: The Free Press.

Ruben BD, Stewart LP. (2006). Communication and Human Behavior. 5th Edition, Boston (US): Pearson Education.

Sambandam R, Hausser G. (1998). An Alternative methods of reporting customer satisfaction scores. Quirk's Marketing Research Review. Retrieved July 19, 2019 from https://www.trchome.com/docs/2alternative-method-of-reportingscores/file .

Sekaran U, Bougie R. (2013). Research Methods or Business, $6^{\text {th }}$ ed. New Jersey: John Wiley and Sons, Inc.

Supranto J. (2001). Pengukuran Tingkat Kepuasan Pelanggan untuk Menaikkan Pangsa Pasar. Jakarta: PT. Rineka Cipta.

Zeithaml VA, Bitner MJ, Gremler DD. (2006). Service marketing: Integrating customer focus across the firm (4th ed.). New York, NY: McGraw-Hill/Irwin. 